\title{
ROBO SOCCER SEBAGAI MEDIA EDUKASI PENGENALAN TEKNOLOGI ROBOTIKA PADA SISWA DI SEKOLAH MENENGAH ATAS
}

\author{
Yohanes Calvinus ${ }^{1}$ dan Endah Setyaningsih ${ }^{2}$ \\ ${ }^{1}$ Program Studi Teknik Elektro, Universitas Tarumanagara \\ Email: yohanesc@ft.untar.ac.id \\ ${ }^{2}$ Program Studi Teknik Elektro, Universitas Tarumanagara \\ Email: endahs@ft.untar.ac.id
}

\begin{abstract}
Robotics technology has now become a technological requirement for all students, both at the elementary school, junior high school and high school level. In fact in some private and public schools the need for education in robotics technology is only a discourse and cannot be realized properly. Many of these schools are trying to work with several agencies providing private education services for robotics. The lack of human resources and knowledge about robotics among high school students has caused these students to not know or lack in participating in the event that should have been the driving force behind the industrial revolution 4.0 about automation and robotics. Even in Jakarta there are not many competitions in the form of robotics competitions that can be participated by high school students. The community engagement team at Tarumanagara University conducted workshops and robot competitions in the form of robo soccer, which also functioned as a media for robotics technology education for high school students. High school students are introduced to robot components in the form of electrical and mechanical components, also about programming. Students are also asked to assemble these components and the results are in the form of robo soccer. These high school students are very happy and enthusiastic about this activity, because curiosity about robots can be achieved. Students from various schools are also active in participating in the Edurobocup Contest organized by the Electrical Engineering study program at Tarumanagara University. It is hoped that this activity can be routinely carried out every year, so that robotics technology can be known while students are still in high school.
\end{abstract}

Keywords: Robo Soccer, Robot Technology, High School, and educational media.

\begin{abstract}
ABSTRAK
Teknologi Robotika saat ini telah menjadi suatu kebutuhan teknologi bagi seluruh pelajar, baik tingkat Sekolah Dasar, Sekolah Menengah Pertama, maupun Sekolah Menengah Atas. Kenyataannya di beberapa sekolah swasta dan negeri kebutuhan pendidikan akan teknologi robotika ini hanya menjadi wacana dan belum dapat terealisasi dengan baik. Banyak sekolah-sekolah tersebut berusaha bekerjasama dengan beberapa instansi penyedia jasa pendidikan swasta untuk robotika. Minimnya sumber daya manusia dan pengetahuan tentang robotika di kalangan siswa SMA menyebabkan siswa tersebut tidak tahu ataupun kurang dalam mengikuti ajang yang seharusnya menjadi pendorong kemajuan revolusi industri 4.0 tentang otomasi dan robotika. Bahkan di Jakarta belum banyak kompetisi berupa perlombaan robotika yang dapat diikuti oleh siswa SMA. Tim pengabdian kepada masyarakat Universitas Tarumanagara melakukan workshop dan lomba robot berupa robo soccer, yang sekaligus difungsikan sebagai media edukasi teknologi robotika bagi siswa SMA. Siswa SMA dikenalkan tentang komponen robot yang berupa komponen elektrik dan mekanik, juga tentang pemrograman. Siswa juga diminta merakit komponenkomponen tersebut dan hasilnya berupa robo soccer. Siswa SMA ini sangat senang dan antusias mengikuti kegiatan ini, karena keingintahuan tentang robot dapat tercapai. Siswa dari berbagai sekolah juga aktif dalam mengikuti Lomba Edurobocup yang diselenggarakan oleh program studi teknik elektro Universitas Tarumanagara. Diharapkan kegiatan ini dapat rutin dilakukan tiap tahun, sehingga teknologi robotika dapat dikenal saat siswa masih di SMA.
\end{abstract}

Kata kunci: Robo Soccer, Teknologi Robot, SMA, dan media edukasi.

\section{PENDAHULUAN}

Teknologi Robotika saat ini telah menjadi suatu kebutuhan teknologi bagi seluruh pelajar, baik tingkat Sekolah Dasar, Sekolah Menengah Pertama, maupun Sekolah Menengah Atas. Banyak 
sekolah-sekolah tersebut berusaha bekerjasama dengan beberapa instansi penyedia jasa pendidikan swasta untuk robotika. Kenyataannya di beberapa sekolah swasta dan negeri kebutuhan pendidikan akan teknologi robotika ini hanya menjadi wacana dan belum dapat terealisasi dengan baik. Universitas Tarumanagara terkenal sebagai universitas swasta yang memiliki pengembangan teknologi robotika di kampus sebagai unit kegiatan mahasiswa yang dikembangkan melalui Fakultas Teknik. Teknologi Robotika ini dianggap menjadi nilai tambah untuk kegiatan mahasiswa maupun nilai tambah eksklusif yang menjadi pembeda antara Universitas Tarumanagara dengan universitas swasta lainnya. Pengembangan teknologi robotika ini, selain menjadi media untuk menempa mahasiswa dalam pengembangan diri, juga menjadi kegiatan untuk mengikuti berbagai ajang lomba robot, baik tingkat nasional maupun tingkat internasional. Dosen sebagai pembimbing kegiatan robotika, menjadikan kegiatan robotika ini menjadi kegiatan tri darma universitas.

Banyak siswa SMA yang belum mengetahui dan belajar tentang robotika. Minimnya sumber daya manusia dan pengetahuan tentang robotika di kalangan siswa SMA menyebabkan siswa tersebut tidak tahu ataupun kurang dalam mengikuti ajang yang seharusnya menjadi pendorong kemajuan revolusi industri 4.0 tentang otomasi dan robotika. Bahkan di Jakarta belum banyak kompetisi berupa perlombaan robotika yang dapat diikuti oleh siswa SMA. Berdasarkan kondisi ini, para dosen di Fakultas Teknik, khususnya Program Studi Teknik Eletro yang menjadi pembimbing kegiatan robotika, mengambil kesempatan ini untuk menjadikan kegiatan robotika sebagai kegiatan tri darma universitas. Kegiatan ini antara lain berupa pelaksanaan pengabdian kepada masyarakat (PKM) dengan topik robo soccer sebagai media pembelajaran pengenalan teknologi robotika.

Terdapat 3 (tiga) sekolah yang menjadi lokasi kegiatan ini, yaitu SMA Pelita 1, SMA Santo Leo 1, dan SMA Kemurnian 1. Ketiga SMA ini berada di dekat kawasan Universitas Tarumanagara, hal ini menjadi alasan pemilihan SMA tersebut untuk kegiatan PKM. Gambar 1 merupakan tampak depan dari ketiga sekolah tersebut. Ketiga sekolah ini memiliki akreditasi A, dan merupakan sekolah swasta unggulan. Namun karena kebutuhan pengajar masih belum optimal, maka kebutuhan pengajar untuk bidang teknologi robotika menjadi pilihan sekunder. Selain itu guru SMA tidak ada yang berasal dari lulusan yang mengerti teknologi robotika.

Permasalahan yang berupa kurangnya sumber daya manusia/pengajar yang ada di sekolah tersebut, mengakibatkan keingintahuan siswa akan teknologi robotika kurang mendapat tanggapan. Salah satu cara yang dilakukan sekolah tersebut adalah melalui pelajaran ekstra kurikuler yaitu kegiatan dilakukan di luar jam sekolah, namun hal ini membutuhkan biaya extra yang relatif mahal. Untuk itu kegiatan PKM ini berupa workshop merakit robo soccer bagi para siswa dan adanya demo berbagai robot yang telah dikembangkan di fakultas teknik Untar. Siswa setiap sekolah yang dibagi dalam beberapa kelompok, disediakan komponen-komponen mekanik dan elektrik untuk merakit robo soccer. Hasil robo soccer ini dipilih yang terbaik dan karya ini menjadi peserta dalam pertandingan robo soccer yang dilakukan di program studi Teknik Elektro pada bulan Oktober 2018. Pengajar dalam kegiatan workshop, selain diberikan oleh dosen, juga oleh mahasiswa. Tujuannya agar mahasiswa dapat menjadi guru pengajar bagi siswa dan menjadi bekal mahasiswa untuk melatih keberanian, kepimpinan, dan kekompakan tim dalam melakukan kegiatan pelatihan robotika tersebut. 


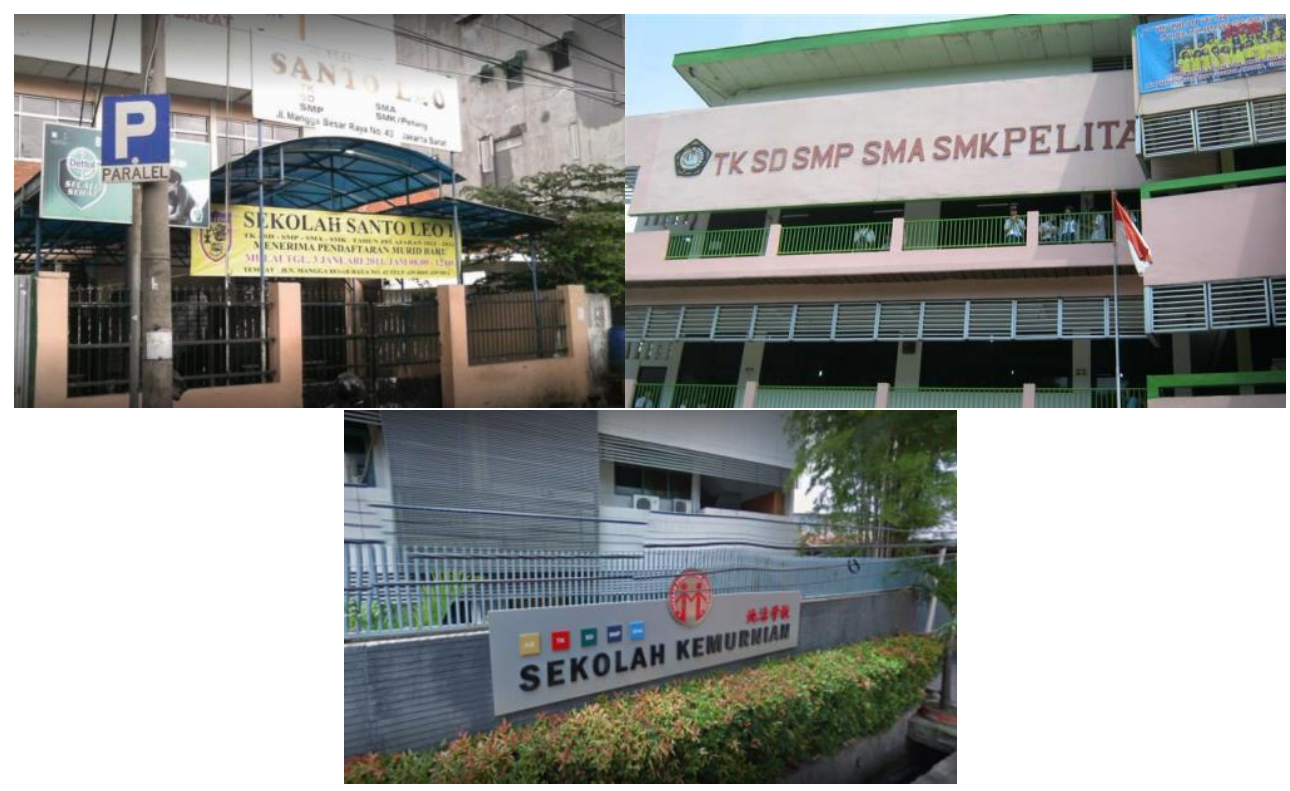

Gambar 1. Tampak depan SMA Pelita 1, SMA Santo Leo 1, SMA Kemurnian 1

\section{METODE PELAKSANAAN PKM}

Kegiatan PKM dilakukan selama 1 (satu) hari untuk tiap sekolah, yaitu dari pukul 8.30 sampai dengan pukul 16.00, dengan waktu istirahat satu jam. Pihak sekolah menyediakan makan siang untuk siswanya dan pelaksana PKM dari Untar menyediakan snack box. Jumlah peserta yang mengikuti kegiatan ini antara 30 - 40 siswa tiap sekolah, yang telah diseleksi oleh pihak sekolah. Semua peralatan dan komponen robot disediakan oleh pelaksana PKM. Pelaksanaan kegiatan PKM dilakukan dalam beberapa tahapan, yaitu:

- Mengenalkan siswa di tiap sekolah tentang komponen-komponen robot, baik komponen elektrik maupun mekanik.

- Membagi siswa menjadi 3 kelompok.

- Merakit robot menjadi robo soccer

- Hasil rakitan ini dipilih salah satu dan diikutkan dalam kompetisi robo soccer yang diadakan oleh program studi Teknik Elektro.

Kegiatan workshop yang dilakukan di tiga sekolah di daerah kota Jakarta yang dekat dengan kampus Universitas Tarumanagara ini, dilakukan bersama antara dosen dan organisasi mahasiswa yang tergabung dalam Ikatan Mahasiswa Teknik Elektro (Imalekta). Mahasiswa ini sebagai instruktur di lapangan yang diperlukan untuk membantu kelompok siswa dalam menyampaikan pembelajaran dan perakitan robot. Adapun komponen robot yang telah dipersiapkan dan di kerjakan oleh para mahasiswa sebelum mengajarkan kepada siswa/i yaitu :

- Pemrograman arduino

- Lembaran jalur pemasangan kabel antara arduino dengan motor driver pada modul bread board. Gambar 2 dan Gambar 3 merupakan rangkaian yang dipersiapkan dan arduino yang telah diprogram. 
Bahasa Program tidak diajarkan pada pelatihan PKM yang diadakan di ketiga sekolah, namun program tersebut sudah dimasukkan kedalam mikrokontroler oleh mahasiswa, dan program tersebut diajarkan pada waktu dan tempat yang berlainan.

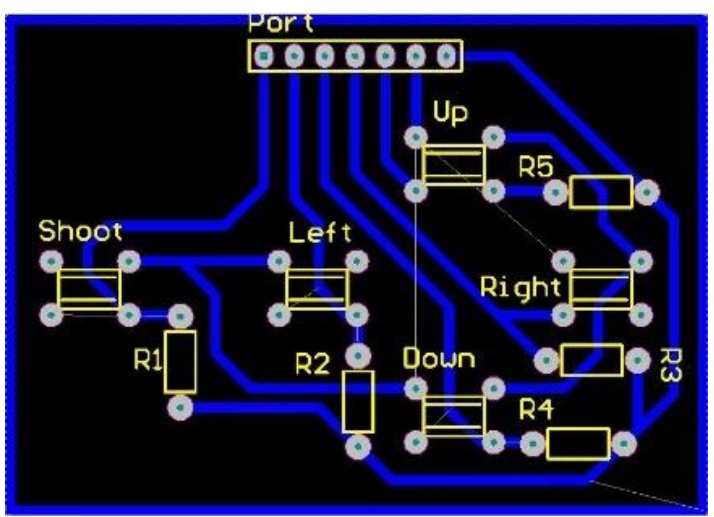

Gambar 2. Rangkaian Keypad Elektronik (DIY)

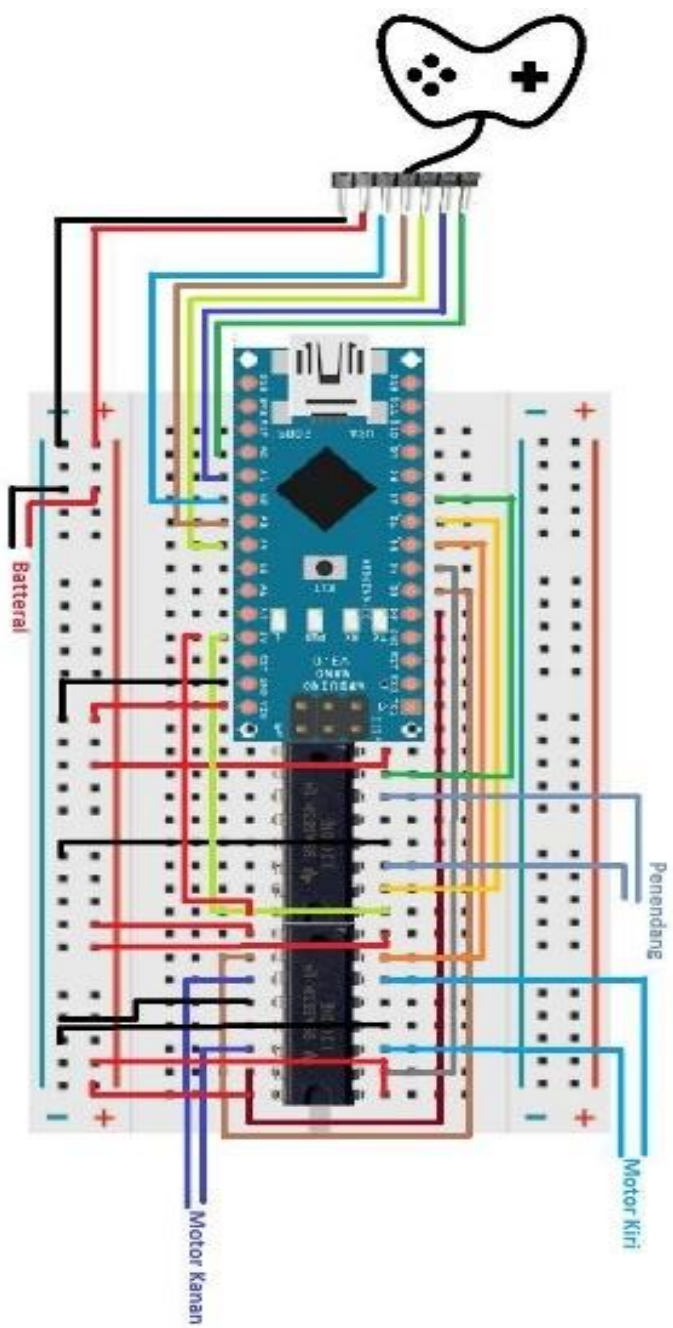

Gambar 3. Arduino yang telah diprogram. 


\section{HASIL DAN PEMBAHASAN}

Teknologi robotika terdiri dari 3 bagian yang penting untuk dipelajari yaitu mekanik, elektrik, dan program. Ketiga program yang diajarkan kepada siswa SMA merupakan pengenalan sehingga diharapkan dapat mengenal dengan baik ketiga pelajaran yang mendukung teknologi robotika. Dalam hal mekanik, robotika soccer bot ini menggunakan motor dc dengan gear box untuk penggerak roda dan menggunakan motor dc brush untuk aktuator penendang bola [1]. Motor dc dengan gear box digunakan sebagai penggerak robot untuk bergerak maju, mundur, kanan dan kiri. Motor dc dengan gear box ini memiliki tegangan listrik input sebesar 9 Vdc. Sedangkan motor $\mathrm{dc}$ brush juga dipergunakaan tegangan input sebesar $9 \mathrm{Vdc}$. Motor DC gearbox , merupakan motor yang menggunakan transformasi gear agar kekuatan dari putaran motor memiliki kekuatan yang lebih daripada tanpa menggunakan gear box. Gambar 4, menunjukkan gambar motor dc dan gear box. Selain motor dc, dalam mekanik robot soccer ini menggunakan roda statis [2] seperti pada Gambar 5.
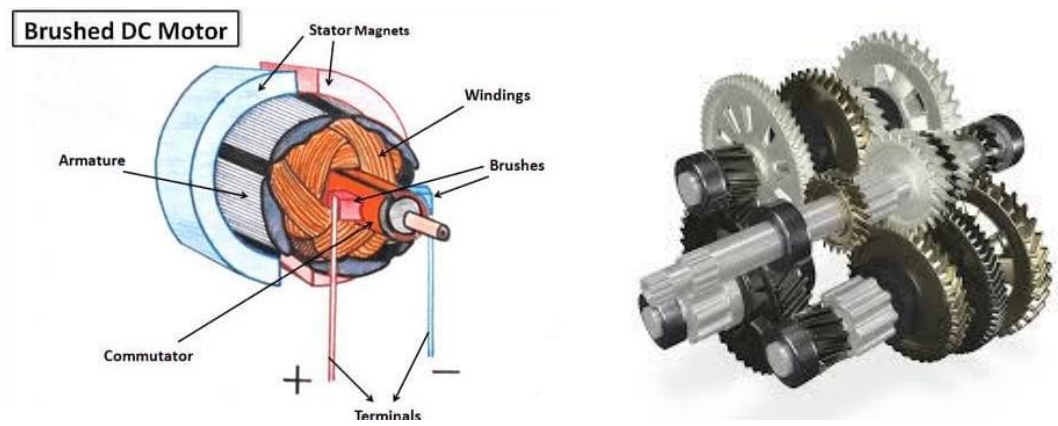

Gambar 4. Motor DC dan Gear Box

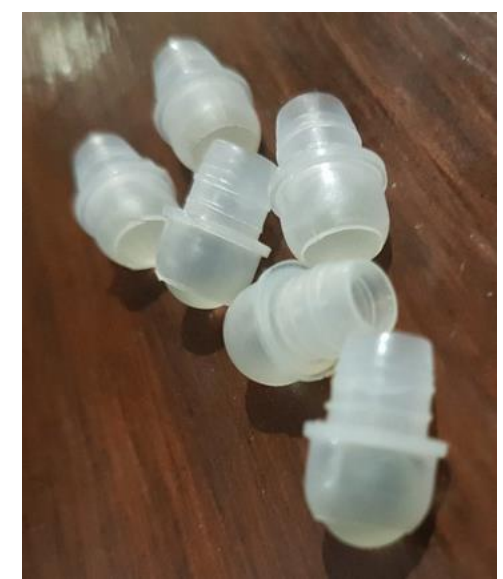

Gambar 5. Roda Bebas dan Statis

Elektrik dalam teknologi robotika merupakan yang paling penting [4], sehingga dalam proses di lapangan, yang paling lama yaitu merakit bagian elektronika dari komponen robotika. Elektronika yang dipergunakan sebagai berikut : Keypad, modul Arduino, dan Motor DC, seperti pada Gambar 2 dan Gambar 3. Pada proses ini terdapat juga proses solder menyolder sehingga dalam proses nya diajarkan kepada siswa agar mengenal proses pembuatan dari tahap awal. Power untuk robot soccer menggunakan baterai $9 \mathrm{~V}$, alkaline baterai tersebut digunakan karena tegangan dan arus yang lebih besar. Pemrograman dalam hal ini menggunakan board Arduino nano [3] dan software dari arduino IDE. Pemrograman tidak diberikan kepada siswa SMA karena masih sulit dimengerti. 
Program ini dilakukan oleh mahasiswa dan hanya diberikan pengantar sebagai pengetahuan siswa SMA, Gambar 6 adalah tampilan program Arduino di komputer. Gambar 7 merupakan gambaran dari hasil akhir dari robot yang akan dihasilkan. Robot ini diberikan kepada sekolah yang menjadi tempat tujuan pendidikan dan diberikan pembinaan. Gambar 8 merupakan gambaran agar robot dapat di modifikasi lebih baik.

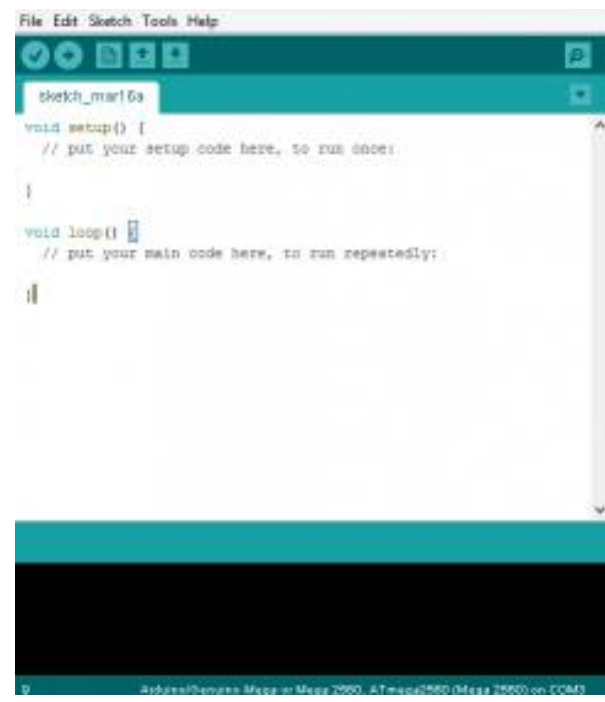

Gambar 6. Tampilan program Arduino di Komputer.

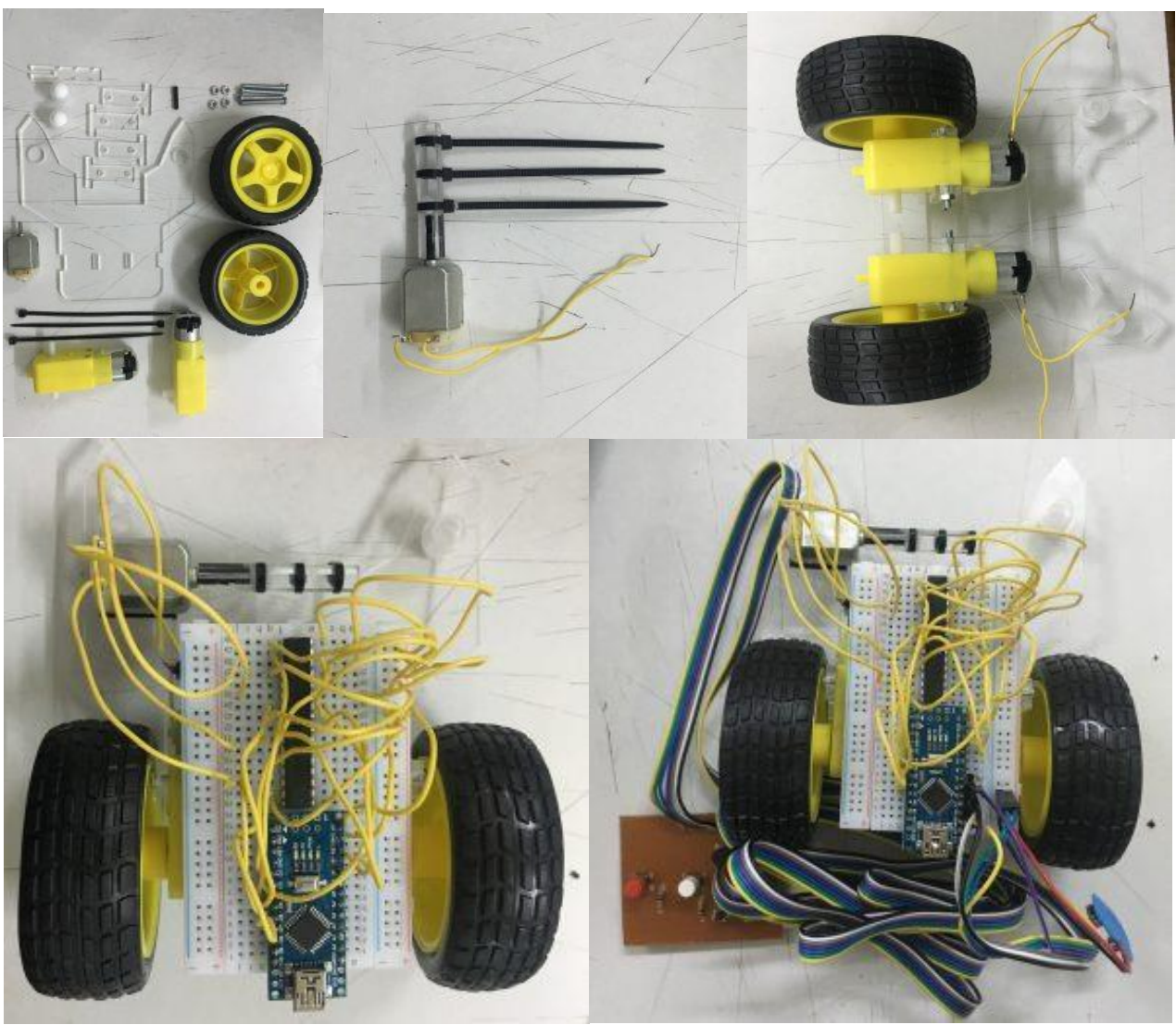

Gambar 7. Prototipe Robot yang Diajarkan kepada siswa SMA 


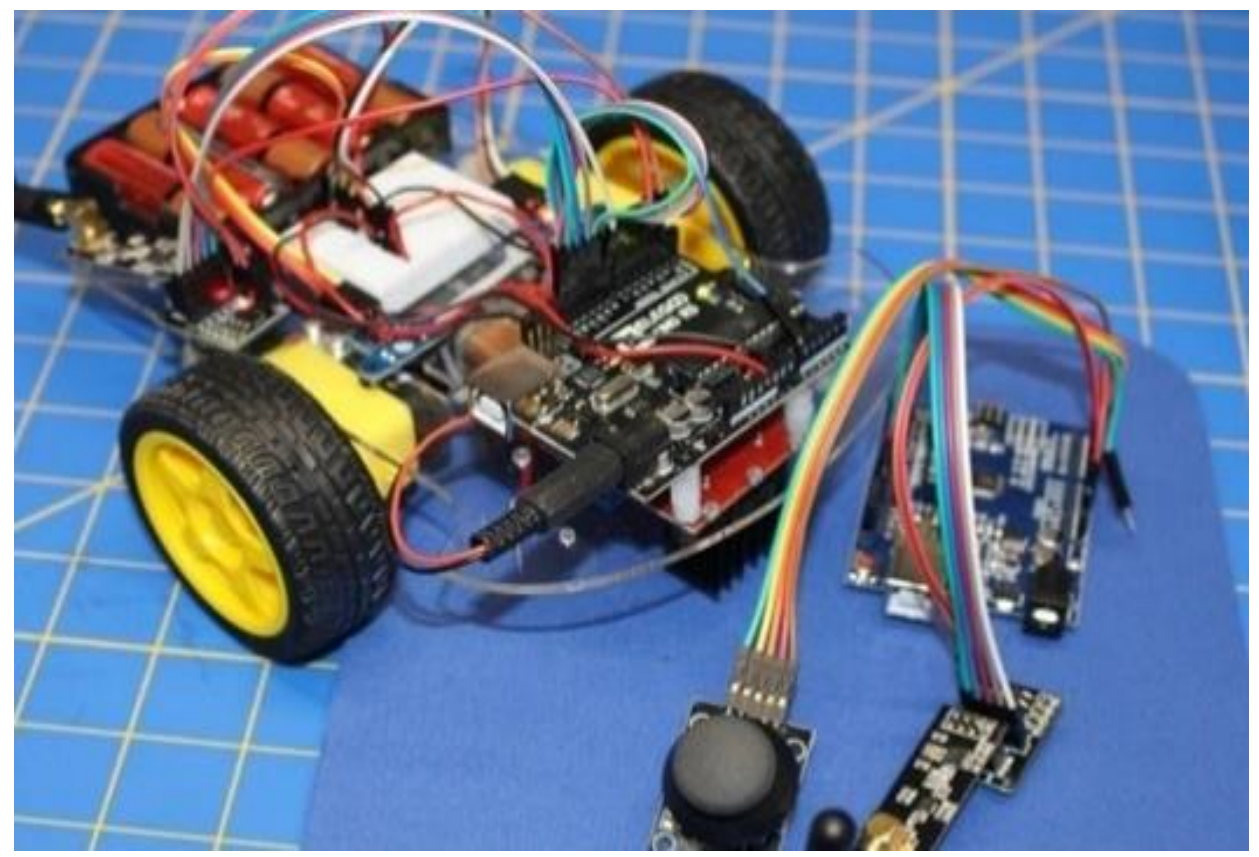

Gambar 8. Modifikasi Akhir
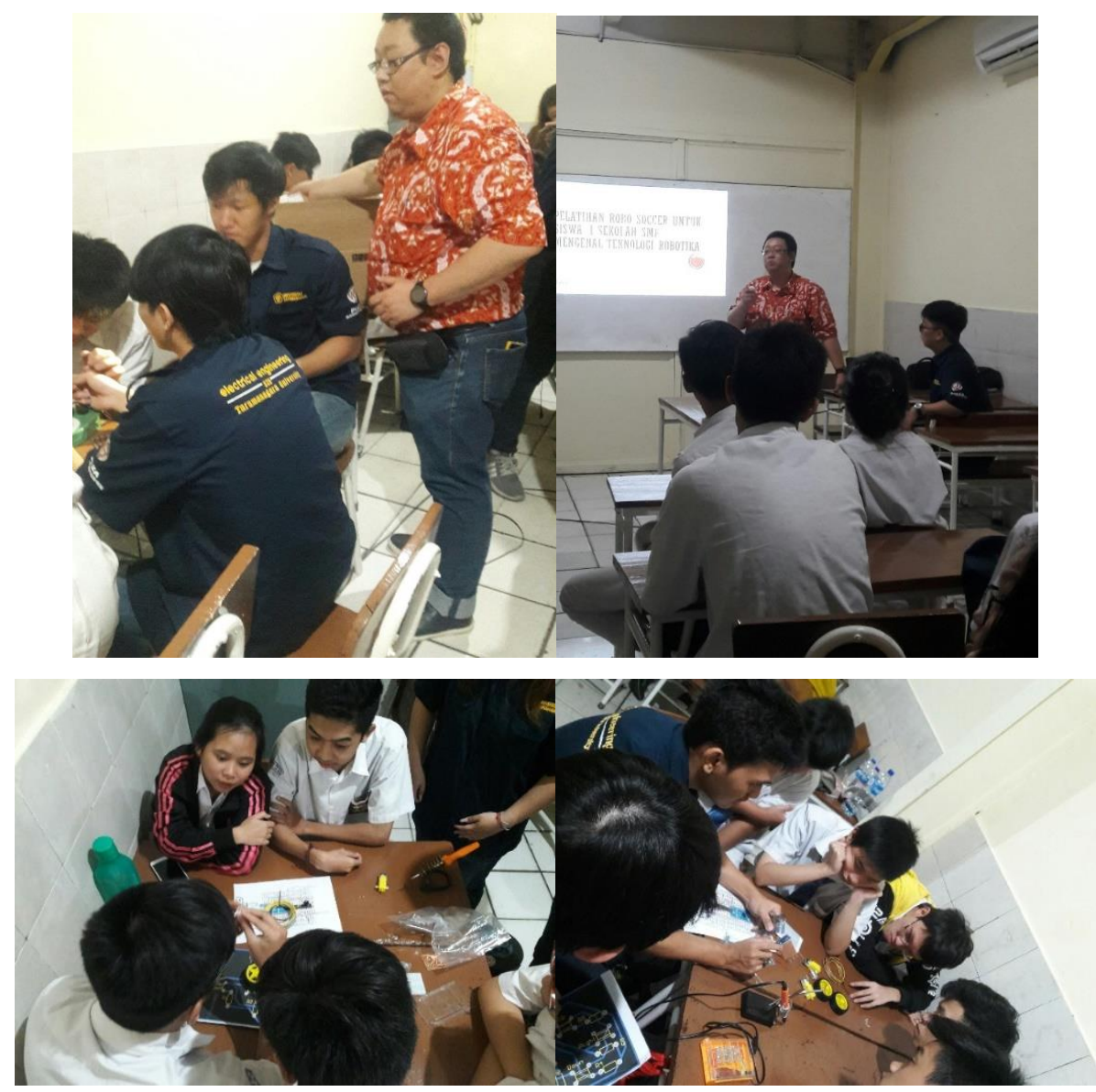

Gambar 9. Gambar kegiatan di salah satu sekolah Pelita 1 


\section{KESIMPULAN DAN SARAN}

Kegiatan pada ketiga sekolah telah berlangsung dengan baik, siswa dari ketiga sekolah sangat antusias dan senang mengikuti workshop yang diberikan oleh tim PKM dan mahasiswa dari Universitas Tarumanagara ini. Murid-murid SMA baik kelas 10 hingga kelas 12 sangat positif dan tanggap dalam mengikuti kegiatan perancangan robo soccer di sekolah masing-masing. Hal ini terlihat dari keikutsertaan tiga sekolah ini dalam Lomba Edurobocup yang diselenggarakan oleh program studi Teknik Elektro. Tim dari SMA Santo Leo yang mengikuti kegiatan ini keluar sebagai juara ke -1 untuk lomba kategori lomba robot sepakbola beroda.

Kegiatan ini sangat di respons positif baik guru dan murid, namun mereka sangat berharap ada kerjasama yang dapat dibuat oleh pihak Untar dan sekolah agar kegiatan ekstra ini dibuat menjadi suatu kegiatan rutin.

\section{UCAPAN TERIMA KASIH (Acknowledgement)}

Terimakasih kepada Direktorat Penelitian dan Pengabdian kepada Masyarakat yang telah memberikan dana untuk terselenggaranya kegiatan PKM ini.

\section{REFERENSI}

RoboHub, "Robot Soccer," 2018. [Online]. Available: https://robohub.org/tag/robot-soccer/. [Diakses 2408 2018]

Saiyam, "The Soccer Robot," 2018. [Online]. Available: https://www.instructables.com/id/TheSoccer-Robot/. [Diakses 2408 2018]

J. D. Warren, Arduino Robotics, Berlin, Germany: Springer Verlag Berlin and Heidelberg GmbH Co KG, 2011

E. Wise, Robotics Demystified, USA: Mcgraw-Hill, 2009 